\title{
A MINERALOGIA E PARAGÊNESE DOS VEIOS QUARTZOSOS SULFETADOS AURÍFEROS DA REGIĀO DO PIRIRICA,VALE DO RIBEIRA, SP
}

\author{
S.A.A.Nogueira ${ }^{1}$
}

A.P.Barbour ${ }^{2}$

\section{RESUMO}

As mineralizaçōes filloneanas auríferas da regiāo do Piririca, Vale do Ribeira, Sāo Paulo, de características epigenéticas, estāo relacionadas a uma zona de cisalhamento, limitada pelos lineamentos regionais Agudos Grandes e Ribeira. Estratigraficamente a região faz parte de uma seqüência de rochas metavulcano-sedimentares, com metabásicas associadas, de baixo grau metamórfico, pertencente à Formação Perau, do Proterozóico Médio.

O estudo da mineralogia dos veios mineralizados apresenta pirita e arsenopirita como os minerais mais abundantes entre os sulfetos estudados. Em quantidades subordinadas observam-se: calcopirita, boulangerita, bournonita, jamesonita, tetraedrita, blenda, galena, bornita, ilmenita e ouro. Quartzo leitoso branco constitui o mineral de ganga dominante.

A tentativa de estabelecimento de uma paragênese temporal entre os minerais acima considerados coloca pirita, arsenopirita e ilmenita como anteriores a uma fase de brechaçáo/milonitização, após a qual cristalizaram-se os outros minerais relacionados, geralmente preenchendo vênulas e fraturas nos dois sulfetos principais. $\mathrm{O}$ ouro, quando aparece, preenche fraturas e cavidades da pirita e arsenopirita.

\section{ABSTRACT}

The gold-bearing veins from the Piririca region, Ribeira Valley, State of São Paulo, Brazil, show epigenetic features and seem to be mainly related to a ductile-brittle shear zone, subordinate to the Agudos Grandes and Ribeira regional tectonic lineaments. Stratigraphically, presents the area a sequence of metavolcano-sedimentary rocks with

\footnotetext{
Instituto Geológico, Secretaria do Meio Ambiente do Estado de Såo Paulo.

${ }^{2}$ Departamento de Geologia Económica e Geofisica Aplicada, Instituto de Geociências/USP, Săo Paulo.
} 
associated metabasic rocks, characterized by low-grade metamorphism. These rocks are correlated with the Middle Proterozoic Perau Formation.

Within the veins, pyrite and arsenopyrite are the most abundant sulphide minerals, with the following minerals having been detected in subordinate quantities: chalcopyrite, boulangerite, bournonite, jamesonite, tetrahedrite, sphalerite, galena, bornite, ilmenite and gold. Milky quartz is the dominat gangue.

In the tentative preliminary paragenetic sequence proposed here, coarsegrained pyrite, arsenopyrite and ilmenite are considered as representing the first phase of sulphide deposition and have been affected by a brecciation/mylonitization deformation episode. The other minerals mentioned above represent a post-deformation phase that occurs in veinlets and fractures, cutting crystals of pyrite and arsenopyrite.

\section{INTRODUÇÃo}

A regiâo do Piririca localiza-se no Município de Iporanga, Vale do Ribeira, extremo sul do Estado de São Paulo (Fig. 1).

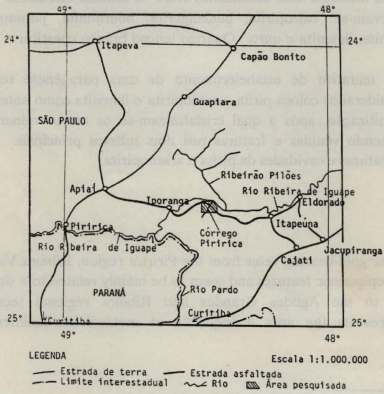

Figura 1 - Mapa de localização. 
Esta área encontra-se inserida em uma seqüência de rochas metavulcanosedimentares, com metabásicas associadas, de baixo grau metamórfico, e relacionada à Formação Perau, definida originalmente por PIEKARZ (1981) e TAKAHASHI et al. (1981) (Fig. 2). Os sedimentos que hoje constituem as seqüencias metamórficas da Faixa de Dobramento Apiaí (HASUI et al., 1976), segundo TASSINARI et al. (1990), depositaram-se entre 1,8 e 1,5 Ga., sofrendo um metamorfismo entre 1,3 e 1,0 Ga., com superimposiçāo de um evento metamorfico datado em $700 \mathrm{Ma}$., do Proterozoico Superior.

A regiăo é situada dentro de uma faixa de rochas orientadas NE-SW, limitada por lineamentos de expressăo regional denominados lineamentos Agudos Grandes e Ribeira, de características transcorrentes, que definem para a área diversas zonas de cisalhamento (EBERT et al, 1988).

Foram detectadas na regiáo, pelo Projeto Eldorado (CPRM, 1982), diversos veios de quartzo sulfetados contendo $\mathrm{Au}$ e $\mathrm{Ag}$, de caráter epigenético, associados freqüentemente às rochas metabásicas, embora ocorram também em metasedimentos.

As rochas metabásicas acham-se intercaladas concordantemente nos metasedimentos finos (ardosias, filitos e metaritmitos), e são constituídas por uma associação de anfibolios da série tremolita-actinolita, plagioclásio sódico (albita), epídoto-zoisita e clorita, típica do grau fraco de WINKLER (1977). Estudos petrograficos sugerem para essas rochas uma natureza intrusiva, provavelmente sub-vulcanica, com composiçáo original de um gabro ou diabásio.

O presente trabalho é uma compilaçáo de parte da pesquisa desenvolvida na dissertaçăo de mestrado de Sonia A.A.Nogueira, feita sobre a área em questão e tem como objetivo mostrar a mineralogia das mineralizaçóes auriferas e estabelecer sua provável paragenese (PADCT/FINEP 4286054500).

\section{ORIGEM DAS MINERALIZAÇÕ̃ES AURÍFERAS DA REGIÃo DO PIRIRICA}

As mineralizaçōes filoneanas auríferas săo de natureza epigenética e estão espacialmente relacionadas a uma zona de cisalhamento de direçăo $\mathrm{N} 40-45^{\circ} \mathrm{E}$.

O conhecimento do comportamento estrutural da regiāo considerada e suas mineralizações é ainda muito limitado, permitindo apenas sugerir, com base em modelos de zonas de cisalhamentos (RAMSAY, 1980) e trabalhos específicos em áreas com mineralizaçóes relacionadas a zonas deste tipo (COLVINE et al., 1984; HODGSON, 1988 e 1989, entre outros), que as mineralizaçóes da área do Piririca estariam ocorrendo num sistema de veios associados a uma zona de cisalhamento de comportamento dúctil-rúptil, com movimentação dextral.

Os veios mineralizados mais significativos estão hospedados em rochas metabásicas, geralmente milonitizadas e brechadas, e, subordinadamente, em metasedimentos. Estudos petrográficos e químicos realizados nessas rochas mostram evidências de alteração hidrotermal, como resultado da interação fluido mineralizante - rocha encaixante. 


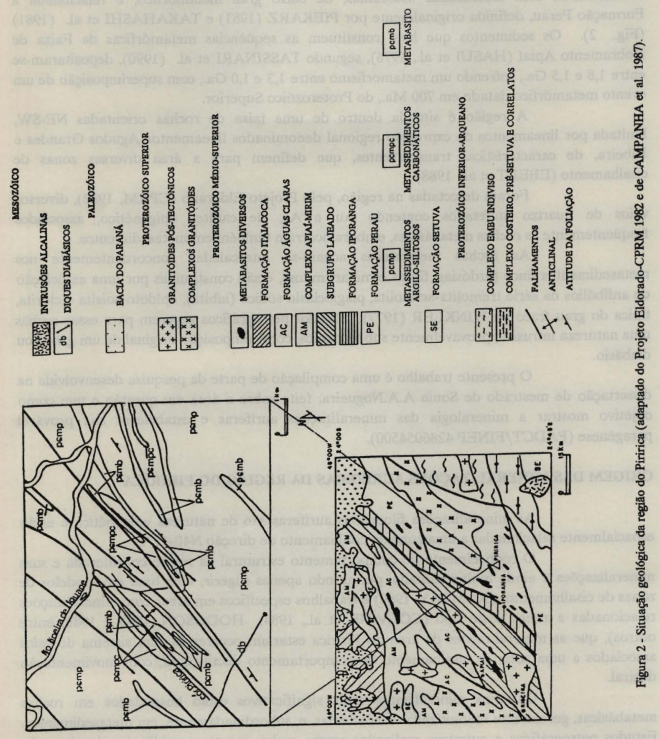


Os dados de análises isotópicas de $\mathrm{Pb}$ efetuadas em amostras de galena associadas aos veios de quartzo sulfetados da região do Piririca, aproximam-se dos dados determinados em galenas de depósitos plumbo-argentíferos do Vale do Ribeira (TASSINARI et al, 1990), que sugerem para as soluçóes mineralizantes uma origem crustal, por processos de remobilizaçáo do $\mathrm{Pb}$ das rochas encaixantes, associados a eventos metamórficos regionais, de idades entre 1,4 e $1,1 \mathrm{Ga}$.

Estudos microtermométricos de inclusões fluídas em quartzo dos veios revelaram a presença de inclusóes do tipo carbônicas, aqüo-carbônicas e eminentemente aqủosas, que forneceram dados para indicar fluidos mineralizantes aqüosos, ricos em $\mathrm{CO}_{2}$ ( $>25$ moles $\% \mathrm{CO}_{2}$ ), de baixa salinidade ( $<11$ eq\% peso em $\mathrm{NaCl}$ ), com temperaturas de deposição de moderadas a altas $\left(200-400^{\circ} \mathrm{C}\right)$ (NOGUEIRA, 1990).

As mineralizaçōes auriferas da região do Piririca e outros depósitos de ouro detectados em áreas adjacentes no Vale do Ribeira, todos eles associados a zonas de cisalhamento em sequência de rochas metavulcano-sedimentares de baixo grau metamórfico, podem ser consideradas epigenéticas, seguindo um modelo metamórfico de derivaçáo de fluidos aqüosos ricos em $\mathrm{CO}_{2}$. Esses fluidos teriam sua origem a partir da devolatilizaçáo dos terrenos metamorficos, com as zonas de cisalhamento representando elementos fundamentais nos processos de canalização dos fluidos hidrotermais e de interaçăo fluido-rochas encaixantes.

\section{MINERALOGIA DAS MINERALIZAÇŌES}

A observaçăo dos veios mineralizados detectados na área em questão permitiu, através de um estudo de caráter preliminar, sugerir um provável zoneamento para estas mineralizaçōes. Em alguns veios desenvolve-se próximo à rocha encaixante uma banda constituída de quartzo de cor escura, ganulaçăo fina, com pequena quantidade de sulfetos finamente disseminados, constituídos principalmente por pequenos cristais de pirita.

A seguir, em direçăo ao interior do veio passa-se para uma banda de quartzo leitoso, bastante comum a todas as mineralizaçōes da área, geralmente estéril ou com raro sulfeto, onde o quartzo mostra uma estrutura boudinada e/ou estirada, e às vezes fraturada. Esta banda envolve uma faixa central de sulfetos maciços constituídos principalmente por pirita e arsenopirita, e subordinadamente de calcopirita, boulangerita, bournonita, jamesonita, galena, blenda, tetraedrita e bornita, formando associaçóes em que apenas alguns comparecem, nem sempre presentes em todos os veios e onde o ouro ocorre normalmente associado aos dois sulfetos principais. Os sulfetos dessa faixa comumente invadem a banda de quartzo que a envolve, preenchendo pequenas fraturas em seu interior. A ganga é essencialmente quartzosa, com carbonato em quantidades subordinadas.

Alguns minerais de alteraçâo supérgena foram observados tais como: covelina, calcocita, limonita, goethita/lepidocrocita, além de outros não determinados. 


\section{DESCRIÇÃO DOS MINERAIS DE MINÉRIO}

O estudo descritivo dos minerais de minério foi realizado essencialmente com amostras da banda de sulfetos maciços. As características texturais das fases mineralógicas identificadas săo apresentadas a seguir.

\section{Pirita}

A pirita, juntamente com a arsenopirita, são os dois sulfetos mais abundantes das mineralizaçóes estudadas, chegando muitas vezes a perfazerem mais de $90 \%$ dos demais minerais opacos presentes.

Apresenta-se geralmente como cristais euhedrais a sub-euhedrais, com contornos geométricos definidos, porém com bordas irregulares. Esses cristais podem aparecer disseminados e isolados na ganga ou formando agregados irregulares. A dimensāo dos diâmetros dos grãos varia amplamente desde muito finos (poucas micra) até $3 \mathrm{~mm}$. Grande parte dos cristais de pirita acha-se fraturada ou mesmo cataclasada, às vezes exibindo uma textura milonítica, com fraturas irregulares (Fotomicrografia 1).

Aspecto comum da pirita é a presença de várias inclusóes de ganga, e de fraturas preenchidas principalmente por calcopirita e boulangerita.

Foi identificada ainda, pirita de granulação mais fina, com cristais euhedrais e sem fraturamento, em vênulas nitidamente posteriores às piritas de granulação mais grossa (Fotomicrografia 1).

\section{Arsenopirita}

Arsenopirita constitui o segundo sulfeto mais abundante na mineralização. Apresenta hábito geralmente idiomórfico, com seçóes retangulares, romboédricas, ou uma combinaçăo dessas duas formas geométricas, podendo aparecer como cristais xenomorfos. Ocorre esparsa na ganga quartzosa, isolada ou formando agregados irregulares, com granulaçáo semelhante aos cristais de pirita. Mostra-se igualmente fraturada, exibindo algumas vezes textura cataclástica milonítica, e raramente se observa preenchimento dessas fraturas por calcopirita ou outro mineral. Participa também dos agregados de pirita, formando uma massa contínua de sulfetos idiomorficos (Fotomicrografia 2).

\section{Calcopirita - Bornita}

A calcopirita ocorre nitidamente em menor quantidade do que a pirita e a arsenopirita, sendo no entanto um mineral comum nos veios estudados.

Apresenta-se com hábito xenomorfo formando agregados granulares com diâmetro médio desde poucas micras até $1 \mathrm{~mm}$. Ocorre na ganga quartzosa, isolada ou associada a outros minerais como boulangerita, blenda, bornita, bournonita, tetraedrita e galena. Pode aparecer também bordejando arsenopirita e pirita, ou cimentando fragmentos destes dois minerais, às vezes como substituiçáo da pirita. Usualmente preenche fraturas 
nestes dois sulfetos (Fotomicrografia 3).

Bornita ocorre muito subordinadamente em agregado granular xenomorfo, sempre associada à calcopirita.

\section{Boulangerita, Jamesonita, Bournonita, Tetraedrita}

São, todos eles, sulfoantimonietos, e aparecem intimamente associados, ocorrendo freqüentemente disseminados na ganga quartzo-carbonática, junto com calcopirita, galena e blenda.

Mostram hábito xenomorfo, cristalizados em agregados granulares. A boulangerita e a bournonita preenchem comumente fraturas na pirita, e mais raramente na arsenopirita, sozinhas ou associadas com os demais minerais citados (Fotomicrografia 4).

\section{Galena}

A galena ocorre associada principalmente à ganga quartzo-carbonática, isolada ou junto a sulfoantimonietos e blenda, sempre em pequenas quantidades. Comumente é idiomórfica, exibindo as típicas feiçōes triangulares, de arranque.

Aparece também, com hábito xenomorfo, constituindo inclusôes na pirita. Parece mostrar preferencia em se associar com a boulangerita.

\section{Blenda}

É um sulfeto raro na mineralização. Cristalizou-se com hábito xenomorfo, em pequenos grãos ( $0,01 \mathrm{~mm})$ disseminados na ganga. Ocorre ainda como inclusōes na pirita, calcopirita e galena, e às vezes preenche fraturas em grăos brechados de pirita, junto com outros minerais (Fotomicrografia 3 ).

\section{Ilmenita}

Ilmenita ocorre geralmente disseminada na rocha básica encaixante, cristalizada em grāos xenomórficos e quase totalmente substituídos por leucoxênio. A granulação é muito variável, com alguns grãos atingindo $0,8 \mathrm{~mm}$ de diâmetro. Apresentam, às vezes, finíssimas ex-soluçôes de hematita, e em alguns cristais se observa geminação lamelar. Em geral estão intensamente corroídas por minerais de ganga, que produzem estruturas em "esqueletos". É observada ainda, constituindo inclusōes milimétricas na arsenopirita e pirita.

\section{Covelina - Calcocita}

A covelina e a calcocita săo sulfetos encontrados na maior parte das amostras, substituindo a calcopirita. Muitas vezes, manchas ou corpos irregulares de calcopirita săo encontrados dispersos em massa de covelina, formando ilhas. Em algumas situaçóes a alteração da calcopirita em calcocita e covelina origina uma típica textura colofórmica. 


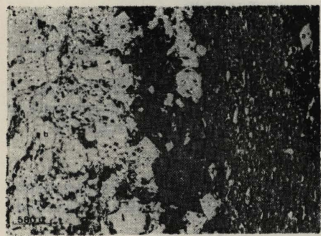

Fotomicrografia 2 - Pirita (a) e arsenopirita (b) de granulação grossa intensamente cataclasadas.

3

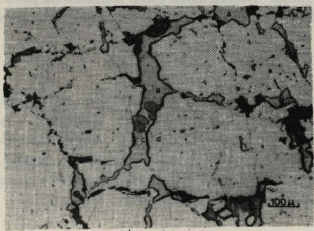

Fotomicrografia 4 - Tetraedrita (a) e boulangerita (b) venulando cristais de granulaçăo grossa de pirita fraturada (c).
Fotomicrografia 1 - Pirita e arsenopirita de granulaçāo grossa mostrando feiçōes de milonitizaçăo e estiramento (a) e de cataclasamento (b). Na parte central, vênula quartzosa com pirita idiomórfica nitidamente posterior.

2

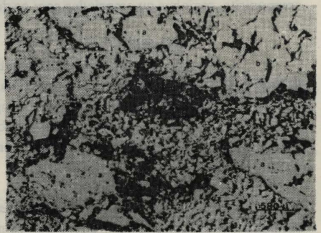

Fotomicrografia 3 - Calcopirita (a), blenda (b) e boulangerita (c) venulando pirita de granulação grossa fraturada (d).

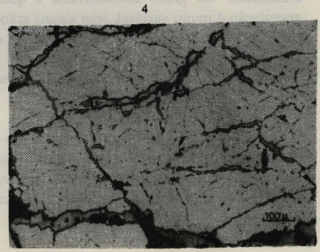




\section{Limonita - Goethita/Lepidocrocita}

Incluem-se aqui todos os óxidos de ferro hidratados supérgenos, freqüentemente associados à pirita e arsenopirita.

A limonita se apresenta, geralmente, como alteração de cristais de pirita, muitas vezes como pseudomorfos. Enquanto que a goethita/lepidocrocita se associa comumente à arsenopirita, formando um agregado amorfo de cor castanha, que nas seçóes polidas aparece como pseudomorfo de arsenopirita.

\section{Sulfatos de cobre}

A identificação desses minerais ao microscópio é muito difícil devido à dimensão dos cristais. A presença desses minerais foi detectada através da observaçăo macroscópica das amostras dos veios aflorantes, nos quais se notou um agregado pulverulento e terroso, de cor verde-clara, que recobre os sulfetos oxidados.

\section{Ouro}

A forma mais usual em que o ouro se apresenta é a de grânulos, com formatos irregulares. A dimensão é muito variável, desde poucas micras até grânulos que atingem $0,12 \mathrm{~mm}$ na maior dimensão.

O ouro ocorre associàdo a cristais de pirita e arsenopirita de granulação grossa, preenchendo fraturas e cavidades. Raramente foi observado na ganga, e quando isto ocorre, está sempre adjacente aos sulfetos citados. Na pirita o ouro apresenta-se geralmente sozinho nas fraturas ou cavidades, raramente ocupando o mesmo espaço com outro mineral (Fotomicrografia 5). No preenchimento de fraturas e vênulas na arsenopirita mostra-se geralmente acompanhado de bournonita (Fotomicrografia 6), ou de um mineral de cor castanha, năo determinado.

O ouro não apresentou, em nenhuma situação observada, inclusôes de outros minerais. Nas amostras estudadas nâo foi detectado macroscopicamente.

\section{RELAÇŌES DE IDADE ENTRE OS MINERAIS DA BANDA SULFETADA}

No estudo das seçóes polidas da banda sulfetada, algumas relaçóes foram observadas entre os minerais opacos. Apenas um número pequeno dessas associaçóes pode fornecer relações de idade com certeza razoável.

As venulaçôes de um mineral em outro săo as relações que forneceram dados mais convincentes sobre a ordem relativa de formação de minerais. Contemporaneidade ou sobreposição provavelmente parecem ter ocorrido, mas nenhum bom critério pode ser evidenciado.

Exemplos destas relaçōes aparecem freqüentemente nos veios estudados, com calcopirita, boulangerita, bournonita, blenda, tetraedrita e ouro venulando ou 
preenchendo fraturas e cavidades de cristais de pirita e arsenopirita (Fotomicrografias 3, 4 e 5). Algumas vezes a calcopirita parece substituir a pirita de granulaçăo grossa, ao redor de suas bordas.

Vênulas de ganga quartzosa, nitidamente posterior, com cristais de pirita idiomórfica sem fraturamento, aparecem cortando pirita e arsenopirita milonitizadas e cataclasadas (Fotomicrografia 1). Essas vênulas podem se constituir também de pequenos cristais idiomórficos de pirita e atravessarem a ganga quartzosa.

Relaçōes geralmente significativas, mas sujeitas a várias interpretações são mostradas por romboédros perfeitos ou cristais irregulares de arsenopirita dentro ou penetrando cristais de pirita, sugerindo arsenopirita tardia em relaçăo à pirita ou, pirita tardia envolvendo cristais já formados de arsenopirita, ou contemporaneidade entre ambas (Fotomicrografia 7). As mesmas relaçôes com pirita no lugar de arsenopirita também são observadas.

Os sulfoantimonietos, que geralmente aparecem intimamente associados, mostram relaçōes significaticas entre si, sugerindo contemporaneidade ou sobreposiçăo.

Limonitização de pirita, arsenopirita transformando-se em hidróxido de ferro (goethita/lepidocrocita), e textura colofórmica de covelina em calcopirita (Fotomicrografia 8) podem ser chamadas de feições subseqüentes desses minerais.

\section{SUSCESSÃo PARAGENÉTICA}

O Quadro 1 procura representar essas relaçōes de idade dos minerais da faixa maciça de sulfetos dos veios mineralizados encaixados em rochas metabásicas.

De acordo com este quadro foi possível identificar três grupos principais de minerais opacos. O primeiro grupo é constituído por pirita e arsenopirita de granulação grossa, que representa os minerais mais abundantes, geralmente presentes em todos os veios, sendo também macroscopicamente os dois sulfetos visiveis. Acham-se freqüentemente fraturados, algumas vezes mostrando feiçóes de milonitizaçāo e estiramento. Não foi possível estabelecer uma relaçăo conclusiva de idade entre esses dois sulfetos. $\mathrm{O}$ conjunto de observaçóes indica tanto a arsenopirita posterior como também anterior à pirita e algumas vezes pode-se pensar em contemporaneidade ou sobreposiçāo entre ambas. Alguns indícios parecem sugerir que haja, neste estádio da mineralização, mais de uma geração de arsenopirita e/ou pirita, como por exemplo onde cristais de arsenopirita com padrōes diferentes de fraturamento estão lado a lado.

O segundo grupo é constituído por calcopirita, boulangerita, bournonita, jamesonita, tetraedrita, galena, blenda, bornita e ouro, presentes em pequenas quantidades nas amostras estudadas. Bornita, blenda e ouro têm uma distribuição menos ampla. Algumas vezes, galena, boulangerita e calcopirita foram observadas macroscopicamente.

Este grupo é claramente tardio em relação aos minerais do primeiro grupo, 
Fotomicrografia 5 - Ouro (a) preenchendo fratura em pirita de granulaçắo grossa (b).

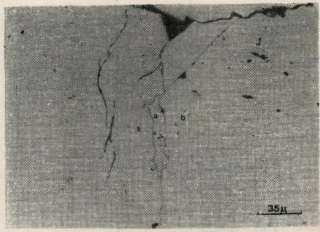

Fotomicrografia 6 - Ouro em grande quantidade (a) em pirita de granulaçăo grossa (b).

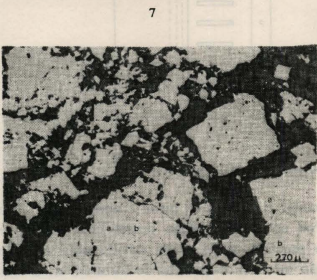

Fotomicrografia 8 - Alteraçåo supérgena de calcopirita (a) em calcocita (b) e covelina (c) originando uma típica textrura coloformica.

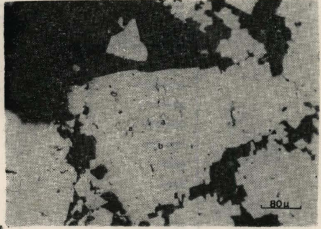

Fotomicrografia 7 - Relaçōes significativas entre pirita (a) e arsenopirita (b) de granulaçâo grossa. Podem indicar arsenopirita tardia com relaçắo à pirita, ou pirita tardia envolvendo arsenopirita já formada, ou contemporaneidade entre ambas.

\section{8}

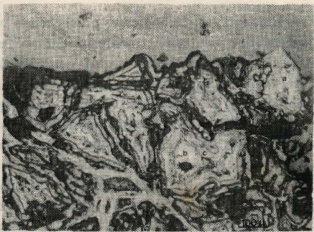


Quadro 1 - Paragênese temporal dos minerais primários e secundários das mineralizaçôes da regiāo do Piririca.

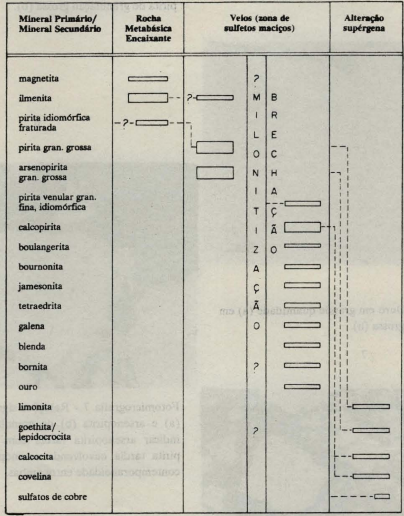

apresentando-se, comumente, preenchendo vênulas e fraturas da pirita e arsenopirita. Isto sugere que em algum momento durante e/ou após a deposiçăo desses dois sulfetos e anteriormente à deposição dos minerais do segundo grupo tenha havido uma fase de brechaçăo. Os minerais do segundo grupo nấo mostram evidências de fraturamentos. As relaçőes entre esses minerais sugerem contemporaneidade ou mesmo sobreposição entre eles.

Além dos minerais citados, observa-se freqüentemente a presença de cristais idiomórficos de pirita, de granulometria mais fina, contida em vênulas (às vezes constituída também por quartzo), nitidamente posteriores aos minerais do primeiro grupo.

O terceiro grupo é constituído de minerais de alteração supérgena: limonita, covelina, calcocita, hidróxido de ferro (goethita/lepidocrocita) e sulfetos de cobre (não determinados), que se formaram a partir dos minerais dos grupos anteriores. 
O ouro foi observado em muitas seçōes polidas dos veios estudados associado preferencialmente a fraturas, vênulas e cavidades de pirita e arsenopirita de granulação mais grossa, do primeiro grupo.

\section{CONSIDERAÇÕES FINAIS}

O estudo da mineralogia das mineralizações filoneanas auríferas da regiấo do Piririca, foi realizado com amostras da banda de sulfetaçăo maciça de veios de quartzo selecionados, onde algumas relaçőes significativas forneceram um quadro da paragenese temporal entre os minerais presentes.

Pirita e arsenopirita de granulação grossa constituem os minerais mais abundantes e antigos, apresentando uma íntima associação com ouro que, assim como calcopirita, boulangerita, bournonita, jamesonita, tetraedrita, blenda, galena e bornita, geralmente preenchem fraturas e vênulas nesses dois sulfetos.

\section{REFERÊNCIAS BIBLIOGRÁFICAS}

COLVINE, A.C.; ANDREWS, A.J.; CHERRY, M.E.; DUROCHER, M.E.; FYON, A.J.; LAVIGNE, M.J.; MACDONALD, A.J.; MARMONT, S.; POULSEN, K.H.; SPRINGER, J.S.; TROOP, D.G. (1984) An integrated model for the origin of archean lode gold deposits. Ontário,Geological Survey. (Open File Report,5524) 98p.

EBERT, H.D.; HASUI, Y.; QUADE, H. (1988) Aspectos da evoluçáo estrutural do Cinturão móvel Costeiro na regiāo da Mina do Perau, Vale do Ribeira, PR. In: CONGRESSO BRASILEIRO DE GEOLOGIA, 35., Belém, 1988. Anais. Belém, SBG. V.5, p.23182331.

HASUI, Y. \& SADOWSKY, G.R. (1976) Evolução geológica do Pré-Cambriano na região sudeste do Estado de São Paulo. Revista Brasileira de Geociências, 6(3):182-200.

HODGSON, C.J. (1988) Precambrian lode gold deposits. Departament Geological Sciences, Queen's University, Kingston, Ontário, Canadá, 214p.

HODGSON, C.J. (1989) The structure of shear-related, vein type gold deposits: a review. Ore Geology Reviews, 4(3):233-273.

NOGUEIRA, S.A.A. (1990) Estudo das mineralizaçóes filoneanas auriferas do depósito de Piririca, Vale do Ribeira, SP. São Paulo, 91p. (Dissertação de Mestrado, Instituto de 
Geociências/USP).

PIEKARZ, G.F. (1981) Reconhecimento de unidades correlacionáveis à seqüência mineralizada do Perau, Estado do Paraná. In: SIMPÓSIO REGIONAL DE GEOLOGIA, 3., Curitiba, 1981. Atas. Curitiba, SBG. V.1, p.148-154.

PROJETO ELDORADO (1982) Relatório Integrado Final de Pesquisa. São Paulo, CPRM/SUREG.

RAMSAY, J.G. (1980) Shear zone geometry: a review. Journal of Strutural Geology, 2:83100.

TAKAHASHI, A.T.; CHIODI FILHO, C.; SILVA, C.R.; BATOLLA JR., F. (1981) Projeto integraçăo e detalhe geológico no Vale do Ribeira. Área Ribeiråo do Perau. Săo Paulo, DNPM/CPRM (Relatório Final).

TASSINARI, C.C.G.; DAITX, E.C.; BARBOUR, A.P.; SATO, K. (1990) Aplicação dos isótopos de $\mathrm{Pb}$ e $\mathrm{Sr}$ na determinação da natureza das fontes das mineralizações de chumbo do Vale do Ribeira - SP/PR. In: CONGRESSO BRASILEIRO DE GEOLOGLA, 36., Natal, 1990. Anais. Natal, SBG. V.3, p.1254-1266.

WINKLER, H.G.F. (1977) Petrogênese das rochas metamórficas. 4.ed. São Paulo, Edgar Blücher; Porto Alegre, UFRGS. 254p. 